\title{
Health and Economic Costs of Physical Inactivity
}

\author{
Joanna Kruk
}

\begin{abstract}
Physical inactivity has reached epidemic levels in developed countries and is being recognized as a serious public health problem. Recent evidence shows a high percentages of individuals worldwide who are physically inactive, i.e. do not achieve the WHO's present recommendation of 150 minutes of moderate to vigorous intensity per week in addition to usual activities. Living in sedentary lifestyle is one of the leading causes of deaths and a high risk factor for several chronic diseases, like cancer, cardiovascular disease, diabetes type 2 , and osteoporosis. This article summarizes evidence for relative risk of the civilization diseases attributable to physical inactivity and the most important conclusions available from the recent investigations computing the economic costs specific to physical inactivity. The findings provide health and economic arguments needed for people to understand the meaning of a sedentary lifestyle. This may be also useful for public health policy in the creation of programmes for prevention of physical inactivity.
\end{abstract}

Keywords: Physical inactivity - civilization diseases - risk factors - economic costs

Asian Pac J Cancer Prev, 15 (18), 7499-7503

\section{Introduction}

Physical inactivity has become one of the most important public issue of 21st century globally (Garrett et al., 2004; Blair 2009; Owen et al., 2009; Owen et al., 2010; Piątkowska, 2012; Rishiraj, 2013), which has lead to increased risk of a range of chronic diseases, including type 2-diabetes, cardiovascular disease, falls, osteoporosis, obesity, certain types of cancer (rectum, colon, breast), and death (Hu et al., 2001; Garrett et al., 2004; WHO, 2005; Kruk, 2009; Dunstan et al., 2010; Tremblay et al., 2010; Clague and Bernestein, 2012; Morrison et al., 2013; Rishiraj, 2013; Sangrajrang et al., 2013; Tayyem et al., 2013; Facts and statistical information sheets, 2014). In contrast, regular moderate physical activity reduces the risk of the most frequent civilization diseases and is associated with well-being (WHO, 2005; Kruk, 2007; Friedenreich et al., 2010a; 2010b; Moore and Sobue, 2010; Anzuini et al., 2011; Lynch et al., 2011; Clague and Bernstein, 2012; Sun et al., 2012; Gao et al., 2013; Kruk and Czerniak, 2013; Kruk and Marchlewicz, 2013; Patel et al., 2013; Steindorf et al., 2013; Amin et al., 2014; Schmid and Leitzman, 2014; Schmid et al., 2014).

The World Health Organization (WHO) guidelines recommend for adults at least $30 \mathrm{~min}$ of intentional physical activity of moderate to vigorous intensity, in addition to usual activities, over 5 or more days per week for good health and reduction of heart diseases, type 2 diabetes, falls (WCRF/AICR, 2007; ACS, 2008; WHO, 2010; AICR, 2014). In the primary prevention of cancer the guidelines recommend for adults at least $60 \mathrm{~min}$ per day of moderate or 30min per day of vigorous physical activity every day. Moreover, there is convincing evidence that regular physical activity of longer duration or greater intensity provides additional health benefit (Warburton et al., 2010). According to this recommendation, the term "physical inactivity" refers to any individual that does not meet the WHO level of physical activity required for good health, i.e. at least $30 \mathrm{~min}$ per week of moderate intensity on at least 5 days per week or at least $25 \mathrm{~min}$ vigorous intensity aerobic exercise on 5 or more days per week (Bull and Groups, 2010; WHO, 2010).

However, the recent research focuses on relationship between the high volumes of time that people spend sitting during waking hours and body physiology (Owen et al., 2010; Rishiraj, 2013). Rishiraj (2013) has summarized the estimated by several authors metabolic dysfunction and health outcomes, resulting from long periods of time spent being inactive or sitting. According to WHO Global Status Report (2010) over $31 \%$ of peoples aged 15 years or older do not meet the WHO's recommended minimum physical activity required for good health. The systematic estimates have shown that high income countries are more than 2-fold in prevalence of insufficiently physically active adults compared to low income countries $(44.5 \%$ vs $19.5 \%$ ). A sedentary behavior of peoples living in developed countries is caused by industrialization, urbanization and mechanization. The changes in domestic tasks, workplace conditions, the daily transport and urban environment produced negative effect on individuals energy expenditure contributing to the individual's physical inactivity (Hamburg et al., 2007; Rishiraj, 
2013; Zhang and Chaaban, 2013). Rates of overweight, defined as body mass index, BMI $>25 \mathrm{~kg} / \mathrm{m}^{2}$, and obesity $\left(\mathrm{BMI}>40 \mathrm{~kg} / \mathrm{m}^{2}\right)$ have been significantly increased since the second half of the $20^{\text {th }}$ century (WCRF/AICR Second Expert Report, 2007; AICR, 2014). Engaging at least $150 \mathrm{~min}$ in moderate or $75 \mathrm{~min}$ in vigorous physical activity weekly, reduction of energy intake, diet low in fat content and rich in vegetables and fruits play the key role in weight management and weight reduction. Based on the recent data it has been estimated that $17-91 \%$ of adults living in developing countries and 4-85\% in developed countries do not meet the WHO's physical activity guidelines for the healthy levels of physical activity recommended by WHO (EUphact, 2008; Oldridge, 2008; WHO Global Status Report NCDs, 2010). For example, the prevalence of physical inactivity was the highest among Canadian adults (85\%), followed by EU members (71\%), Argentina population $(68 \%)$, Polish adults $(64 \%)$, English adults (63\%), Americans (54.1\%), South Africans (52\%), the people living in France (33\%), China (31.1\%) (aged 1569), Thailand (19\%), Mongolia (9\%), and Bangladesh less than 10\% (Martin et al., 2001; Saris et al., 2004; Roux et al., 2008; Drygas et al., 2009; WHO Global Status Report NCDs, 2010; Colley et al., 2011; Department of Health, 2011; Australian Bureau of Statistic 2012; Rishiraj, 2013; Zhang and Chaaban, 2013). These data show that physical inactivity have reached epidemic state in developed countries. As have mentioned above sedentary lifestyle is a primary risk factor for several civilization diseases, premature death and contributes significantly to medical care costs. According to Stevens et al. (2009) "physical inactivity is one of the most important public health problem of the $21^{\text {st }}$ century, and may even the most important".

Knowledge of the impact of physical inactivity/ sedentary lifestyle on the development of several chronic diseases and premature death may encourage individuals to undertake more physically active and healthful lifestyle. Having that in mind, this study summarizes briefly the most important conclusions available from the recent reports dealing with the causal relationships between physical inactivity and the health outcomes and economical costs associated with treating chronic diseases related to sedentary lifestyle.

\section{Consequences of Physical Inactivity for Individuals}

The recent research on physical activity and health often focuses on impact of high volumes of time that people spend sitting during waking hours on body physiology and health care costs (Garret et al., 2004; Warburton et al., 2006; Autenrieth et al., 2009; Brown et al., 2009; Juneau and Potvin, 2010; Owen et al., 2009, 2010; Rishiraj, 2013, Anderson et al., 2014). According to the data reported by Owen et al. (2010) adults, on average, spend $9.3 \mathrm{~h}$ per day in sedentary activities, i.e. about $56 \%$ individual's waking hours. In contrast, the percentage of the leisure time that adults spend doing moderate-vigorous physical activity consists only about $4 \%$. Recently Rishiraj
(2013) summarized the literature findings on metabolic dysfunction and health outcomes resulting from long periods of adults' waking time spent being inactive (e.g. remaining in bed or sitting). This study was based on self-reported participation in leisure-time, household, occupational physical activities, and transportation among Canadian adults. The findings have shown that time spent engaging in household and occupational physical activities were almost four times higher than those from leisure-time physical activity and were comparable within participants categorized as active or very active. The findings were also similar for energy expenditure. The authors further found that the effect of energy expenditure from transportationrelated energy expenditure on the total energy expenditure among this cohort was negligible. Moreover, this research showed that the difference in hours spent in leisure-time physical activity between men categorized as very active $(\mathrm{PAL} \geq 1.90)$ and those classified as inactive (PAL $<1.40)$ was 30min weekly. In women, the difference in the leisuretime activity duration was a little greater (40min) between physically active and physically inactive. Thus, Rishiraj et al. (2013) observed that household and occupational physical activities are important in the overall energy expenditure of individuals who fulfill the WHO physical activity recommendation. It is also interesting to mention about some consequences like microvascular dysfunctionsignificant increase of cholesterol, triglycerides, glucose levels in plasma as well as insulin resistance observed in healthy volunteers remaining in bed for $23.5 \mathrm{~h}$ per day through 5 days (Hamburg et al., 2007).

There is now clear evidence proving that physical inactivity increases the risk of several chronic diseases. The supporting evidence of the impact of physical inactivity on the incidence of several chronic diseases is summarized in Table 1. As can be seen from Table 1, in terms of the magnitude relationship between a disease risk and physical inactivity, the increased risks estimated for colon/rectal cancers have ranged, for example, from $37 \%-100 \%$, from $20 \%-50 \%$ for breast cancer, from $57 \%-100 \%$ for osteoporosis. These data clearly show that physical inactivity is one of the important lifestyle factors contributing to development of several civilization diseases. In this regard, it is worth mentioning that in developed countries physical inactivity is responsible for about $22-23 \%$ deaths from heart diseases, 16-17\% deaths from colon cancer, $15 \%$ deaths from diabetes, $12-13 \%$ deaths from strokes, and $11 \%$ deaths from

Table 1. Relative Risks of the Civilization Diseases Attributable to Physical Inactivity

\begin{tabular}{ll}
\hline Disease category & Risk increase \\
\hline Colon cancer & $37-100 \%$ \\
Breast cancer & $20-50 \%$ \\
Heart diseases & $43-100 \%$ \\
Stroke & $40-100 \%$ \\
Hypertension & $30-50 \%$ \\
Non-insulin dependent diabetes (type 2) & $40-74 \%$ \\
Osteoporosis & $57-100 \%$ \\
\hline
\end{tabular}

*Source: Data summarized based on Refs of Katzmarzyk et al. (2000); Garrett et al. (2004); Roux et al. (2008); Janssen (2012); Zhang and Chaaban (2013) 
breast cancer (WHO, 2002). The recently published data by Lee et al. (2012) present that $6 \%$ of coronary heart disease, $10 \%$ of colon cancer, $10 \%$ of breast cancer, and $7 \%$ of type 2 diabetes in 2008 were described to physical inactivity worldwide. The paper also shows the strong increase of deaths due to physical inactivity compared with 2002 (5.3 million vs 1.9 million) in 2008. Moreover, physical inactivity is also a high risk factor for high blood cholesterol, overweight, obesity, atherosclerosis, musculoskeletal disorder, falls, anxiety and depression (Warburton et al., 2007; WCRF/AICR, 2007; McTiernan, 2008; Friedenreich et al., 2010a; Winzer et al., 2011; Loprinzi et al., 2012; Nunan et al., 2013).

\section{Costs of Physical Inactivity}

The economic costs of physical inactivity have been attempted to estimate in several countries. The studies considered the impact of physical inactivity on the incidence of civilization diseases and death, treating physical inactivity as an independent risk factor. The interest in qualifying physical inactivity as an important contributor of health care costs and lost of productivity continues to grow as the sedentary behavior is at epidemic rates in the developed countries. According to WHO (2010), physical inactivity is the fourth leading risk factor for death worldwide, accounting about 3.2 million deaths worldwide a year (Pratt et al., 2014). The costs attributable to physical inactivity are divided into three fractions: the direct health care costs of treating diseases; the indirect costs, i.e. financial impact of diseases due to physical inactivity on society (productivity loss and workers' compensation), and the costs attributable to premature death from diseases related to physical inactivity (Pratt et al., 2000). It is estimated that in developed countries physical inactivity is responsible for $1.5-3 \%$ of total healthcare direct costs of treatment for chronic diseases (Oldridge, 2008). For example, the direct cost due to physical inactivity represented $2.4 \%$ of total healthcare costs in USA, $1.5 \%$ in UK (Ghoreishi, 2012), and 7.4\% in Czech Republic (Maresova, 2014).

Few authors have quantified the economic costs caused by insufficient physical activity (Table 2). It must be taken into account that the estimated direct costs are more accurate than that indirect costs because the lost of productivity did not include all the sources and loss of quality of life. Further, the estimate of the disease costs proportion and of premature death that may be theoretically caused by physical inactivity, as an independent risk factor, are at all based on population-attributable fraction (PAF) and the relative risk for disease attributable to people exposed and not exposed to the risk (Katzmarzyk et al., 2000). Therefore, the economic costs may be calculated mainly for the diseases for which epidemiological data, meta-analysis provide knowledge on relative risk and PAF for the diseases recognised to be associated with physical inactivity listed in Table 1. Although analysis of economic costs has limitations, like impossibility to identify all person in the population who are physically inactive, techniques used for calculation based on health care payments and risk factors prevalence, it is clear that physical inactivity exerts the negative impact on health outcomes and is associated with considerable economic costs accounted by billion each year. In this respect, it is noteworthy the Piggin and Bairner' review analysis of "the global physical inactivity pandemic" construction and undertaken programme to solve this important problem (Piggin and Bairner, 2014).

In addition, it is also important to citate the American Institute for Cancer Research (AICR/WCRF, 2010) statement that "Americans can prevent $1 / 3$ of the most common cancers staying lean, eating smart, moving more". In 2008 the World Health Organization qualified that one USD invested in promotion intervention to undertake adequate levels of physical activity reduces the economic costs by $\$ 3.2$ in USA (WHO 2008). Also, Cadilhac and co-workers (2011) have developed simulation models that show that a $10 \%$ reduction in physical inactivity causes the decrease of incident cases of disease by 6000 deaths during 2000 and total cost savings of AUD 258 million. Similarly, the calculated cost-effectiveness of interventions by Roux et al (2008) in order to promote adequate physical activity, although a high (ranged between $\$ 14000$ and $\$ 69000$ per quality-adjusted life year) appears profitable. This authors estimate the following considerable reduction of civilization diseases incidence per 100,000:5-15 cases for colorectal cancer, 15-58 cases for breast cancer, 59-207 cases for diabetes type 2, and 140-476 cases for coronary heart disease over lifetime.

In conclusion, the paper provides the health and economic arguments for the need to change the sedentary lifestyle into physically active. Quantification of health consequences and economic costs attributable to physical inactivity creates awareness of the inactivity problem

Table 2. Economic Costs Per Years of Diseases Attributable to Physical Inactivity

\begin{tabular}{lllr}
\hline Country/State & Direct costs & Indirect costs & Source \\
\hline Canada (2007) & \$2.4 billion & \$ 4.3 billion & Janssen (2012) \\
China (2007) & USD 3.5 billion & USD 3.3 billion & Zhang and Chaaban (2013) \\
Australia (2008) & \$ 719 million & \$ 9.299 million & Medibank (2008) \\
Czech Republic (2008) & Total healthcare costs & & Maresova (2014) \\
& Kč 14,637 million & & \\
New Zealand (2010) & \$614 million & \$ 262-396 million & Wellington Regional Strategy 2013 \\
Switzerland (2001) & Sfr 1,579 million & Sfr 805 million & Martin et al. (2001); Scarborough et al. (2011) \\
United Kingdom (2006-2007) & £ 936 million & £ 7,264 million & Allender et al. (2007) \\
California Countries (2006) & USD 7.9 billion & USD 12.3 billion & Chenoweth and Associates, Inc (2009) \\
USA (2003) & Total costs for all adults & & Chenoweth and Leutzinger (2006) \\
& USD 251.11 billion & & \\
*Abbreviations: Kč-Czech korone; Sfr-Switzerland frank & &
\end{tabular}




\section{Joanna Kruk}

and a need of programme for its reduction as a tool of the primary healthcare practice. Thus, the reported data are important for individuals and public health policy for developing policies and intervention that will be useful to improve the public health, to reduce the premature deaths, health care costs, and the indirect costs caused through sickness absence.

\section{References}

Allender S, Foster C, Scarborough P, Rayner M (2007). The burden of physical activity-related ill health in the UK. $J$ Epidemiol Community Health, 61, 344-8.

American Cancer Society (2008). Breast Cancer Facts and Figures 2007-2008, Atlanta, GA: American Cancer Society, Inc.

American Institute for Cancer Research (2010). AICR/WCRF, Policy and Action for Cancer Prevention, 2009. Cancer Facts and Figures, 2010, www. aicr.org.

American Institute for Cancer Research (2014). American can prevent $1 / 3$ of the most common cancers staying lean, eating smart, moving more. Retrieved in June 2014, www.aicr.org.

Amin TT, Al-Hammam A, Al-Mulhin NA, et al (2014). Physical activity and cancer prevention: awareness and meeting the recommendations among adults Saudis. Asian Pac J Cancer Prev, 15, 2597-606.

Anderson AS, Craigie AM, Caswell S, et al (2014). The impact of a body weight and physical activity intervention (BeWEL) initiated through a national colorectal cancer screening programme: randomized controlled trial. BMI, 348, 1823 .

Anzuini F, Battistela A, Izzotti A (2011). Physical activity and cancer prevention: a review of current evidence of biological mechanisms. J Prev Med Hyg, 52, 174-80.

Australian Bureau of Statistics. National Health Survey 2011/2012 (4364.o). October 2012.

Autenrieth C, Schneider A, Doring A, et al (2009). Association between different domains of physical activity and markers of inflammation. Med Sci Sports Exerc, 41, 1706-13.

Blair SN (2009). Physical inactivity: the biggest public health problem of the 21st century. Br J Sports Med, 43, 1-2.

Brown WJ, Bauman AE, Owen N (2009). Stand up, sit down, keep moving: turning circles in physical activity research? Br J Sports Med, 43, 86-8.

Bull FC, Groups EW (2010). Physical activity guidelines in the UK review and recommendations. school of sport, exercise, and health sciences, Loughborough University, Loughborough, UK.

Cadilhac DA, Cumming TB, Sheppard L, et al (2011). The economic benefits of reducing physical inactivity: an Australian example. Int J Behav Nutr Phys Activity, 8, 99.

Chenoweth and Associates, Inc (2009). The economic costs of overweight, obesity, and physical inactivity among California adults-2006. California Center for Public Health Advocacy. Retrieved in September 2009 from http://www. publichealthadvocacy.org.

Chenoweth D, Leutzinger J (2006). The economic cost of physical inactivity and excess weight in American adults. $J$ Phys Activity and Health, 3, 148-63.

Clague J, Bernstein L (2012). Physical activity and cancer. Curr Oncol Rep, 14, 550-8.

Colley RC, Garriguet D, Janssen I, et al (2011). Physical activity of Canadian adults: accelerometer results from the 2007 to 2009 Canadian health measures survey. Health Rep, 22, 7-14.

Department of Health (2011). Start active, stay active: a report on physical activity for health from the four home countries' chief medical officers. Retrieved in July 2013 from http:// www.dh.gov.uk/prod_consum_dh/groups/dh_digitalassets/ documents/digitalasset/dh_128.

Drygas W, Kwasniewska M, Kaleta L, et al (2009). Epidemiology of physical inactivity in Poland: prevalence and determinants in a former communist country in socioeconomic transition. Public Health, 123, 592-7.

Dunstan DW, Healy GM, Sugiyama T, Owen N (2010). Too much sitting and metabolic risk: Has modern technology caught up with us? European Endocrinology, 6, 19-23.

EUphact 2008 http.euphix.org/object_class/euph_physical_ activity.html 2012.02.15.

Facts and statistical information sheets (2014). Costs of physical inactivity. Department of Sport and Recreation. Government of Western Australia, pp.1-4. Retrieved in May 2014 from http://www.dsr.wa.gov.au/accessibility

Friedenreich CM (2010b). Physical activity and breast cancer: review of the epidemiologic evidence and biologic mechanisms. in: Senn H-J, Otto F (eds) Clinical Cancer Prevention, Chap.11. Springer Verlag, Berlin Heidelberg, 188, 125-39.

Friedenreich CM, Neilson HK, Lynch BM (2010a). State of the epidemiological evidence on physical activity and cancer prevention. Eur J Cancer, 46, 2593-604.

Gao Y, Huang Y-B, Liu X-O, et al (2013). Tea consumption, alcohol drinking and physical activity associations with breast cancer risk among Chinese females: a systematic review and meta-analysis. Asian Pac J Cancer Prev, 14, 7543-50.

Garrett NA, Brasure M, Schmitz KH, Schultz MM, Huber MR (2004). Physical inactivity. direct cost to a health plan. Am J Prev Med, 27, 304-9.

Ghoreishi O (2012). Physical inactivity costs economy billions each year. Retrieved in June 2012 from http://www. theepochtimes.com/n2/canada/physical-inactivity-costseconomy-billions-each-year-250939.html.

Hamburg NM, McMackin CJ, Huang AL, et al (2007). Physical inactivity rapidly induces insulin resistance and microvascular dysfunction in healthy volunteers. Arterioscler Thromb Vasc Biol, 27, 2650-6.

Hu FB, Leitzman MF, Shampfer MJ, et al (2001). Physical activity and television watching in relation to risk for type 2 diabetes mellitus in man. Arch Intern Med, 161, 1542-8.

Janssen I (2012). Health care costs of physical inactivity in Canadian adults. Appl Physiol Nutr Metab, 37, 803-6.

Juneau C, Potvin L (2010). Trends in leisure-, transport-, and work-related activity in Canada 1994-2005. Prev Med, 51, 384-6.

Katzmarzyk PT, Gledhill N, Stephard RJ (2000). The economic burden of physical inactivity in Canada. CMAJ, 163, 143540.

Kruk J (2007). Physical activity in the prevention of the most frequent chronic diseases: an analysis of the recent evidence. Asian Pac J Cancer Prev, 8, 325-38.

Kruk J (2009). Physical activity and health. Asian Pac J Cancer Prev, 10, 721-8.

Kruk J, Czerniak U (2013). Physical activity and its relation to cancer risk: updating the evidence. Asian Pac J Cancer Prev, 14, 3993-4003.

Kruk J, Marchlewicz M (2013). Dietary fat and physical activity in relation to breast cancer among Polish women. Asian Pac J Cancer Prev, 14, 2495-502.

Lee I, Shiroma EJ, Lobelo F, et al; Lancet physical activity series working group (2012). Effect of physical inactivity on major non-communicable diseases worldwide: an analysis of burden of disease and life expectancy. The Lancet, 380, 219-29.

Loprinzi PD, Cardinal BJ, Smit E, Winters-Stone KM (2012). 
Physical activity and breast cancer risk. J Exerc Sci Fitness, 10, 1-7.

Lynch BM, Neilson HK, Friedenreich CM (2011). Physical activity and breast cancer prevention. in: Courneya KS, Friedenreich (eds) Physical Activity and Cancer, Recent Results in Cancer Research, Chap. 2. Springer Verlag, Berlin Heidelberg, 186, 13-42.

Maresowa K (2014). The costs of physical inactivity in the Czech Republic in 2008. JPAH, 11, 489-94.

Martin BW, Beeler I, Szucs T, et al (2001). Economic benefits of the health-enhancing effects of physical activity: first estimates for Switzerland. Schweiz. Z Sportmed Sporttramatol, 49, 131-3.

McTiernan A (2008). Mechanisms linking physical activity with cancer. Nat Rev Cancer, 8, 205-11.

Medibank Private (October 2008). The cost of physical inactivity. Retrieved in September 2013 from http://www.medibank. com.au.

Moore MA, Sobue T (2010). Strategies for cancer control on an organ-site basis. Asian Pac J Cancer Prev, 11, 149-64.

Morrison DS, Parr CL, Lam TH, et al (2013). Behavioural and metabolic risk factors for mortality from colon and rectum cancer: analysis of data from the Asian Pacific cohort studies collaboration. Asian Pac J Cancer Prev, 14, 1083-7.

Nunan D, Mahtani KR, Roberts N, Heneghan C (2013). Physical activity for the prevention and treatment of major chronic disease: an overview of systematic review. Systematic Reviews, 2, 56

Oldridge NB (2008). Economic burden of physical inactivity: healthcare costs associated with cardiovascular disease. Eur $J$ Cardiovasc Prev Rehabil, 15, 130-9.

Owen N, Bauman A, Brown W (2009). Too much sitting: a novel and important predictor of chronic disease risk? $\mathrm{Br} J$ Sports Med, 49, 81-3.

Owen N, Healy GN, Matthews CE, Dunstan DW (2010). Too much sitting: the population health science of sedentary behavior. Exerc Sport Sci Rev, 38, 105-13.

Patel A, Keogh JWL, Kolt GS, Schofield GM (2013). The longterm effects of a primary care physical activity intervention on mental health in low-active, community-dwelling older adults. Ageing and Mental Health, 17, 766-72.

Piątkowska M (2012). Self-rated physical activity level across Europe-Poland and other European countries. Biol Sport, 29, 23-31.

Piggin J, Bairner A (2014). The global physical inactivity pandemic: an analysis of knowledge production. Sport, Education and Society, Retrieved from http://dx.doi.org/10 $.1080 / 13573322.2014 .882301$.

Pratt M, Macera CA, Wang G (2000). Higher direct medical costs associated with physical inactivity. Phys Sportsmed, 28, 63-70.

Pratt M, Norris J, Lobelo F, Roux L, Wang G (2014). The cost of physical inactivity: moving into the $21^{\text {st }}$ century. $\mathrm{Br} J$ Sports Med, 48, 171-3.

Rishiraj N (2013). Inactivity: a bad "habit" costing our productive lifestyle. Int J Phys Med Rehabil, 1, 3 .

Roux L, Pratt M, Tengs TO, et al (2008). Cost effectiveness of community-based physical activity interventions. Am J Prev Med, 35, 578-88.

Sangrajrang S, Chaiwerawattana A, Ploysawang P, et al (2013). Obesity, diet and physical inactivity and risk of breast cancer in Thai women. Asian Pac J Cancer Prev, 14, 7023-7.

Saris WHM, Boshuizen HC, Feskens EJM, et al (2004). Physical activity and stroke. A meta-analysis of observational data. Int J Epidemiol, 33, 787-98.

Scarborough P, Bhatnagar P, Wickramasinghe KK, et al (2011). The economic burden of ill due to diet, physical inactivity, smoking, alcohol and obesity in the UK: an update to 200607 NHS costs. J Public Health (Oxf), 33, 527-35.

Schmid D, Leitzmann MF (2014). Association between physical activity and mortality among breast cancer and colorectal cancer survivors: a systematic review and meta-analysis. Ann of Oncol, 25, 1293-311.

Schmid D, Steindorf K, Leitzmann MF (2014). Epidemiologic studies on physical activity and primary prevention of cancer. Deutsche Zeitschrift Sportmedizin, 65, 5-10.

Steindorf K, Ritte R, Eomois PP, et al (2013). Physical activity and risk of breast cancer overall and by hormone receptor status: the European prospective investigation into cancer and nutrition. Int J Cancer, 132, 1667-78.

Stevens RJ, Roddam AW, Spencer EA, et al (2009). Factors associated with incident and fatal pancreatic cancer in a cohort of middle-aged women. Int J Cancer, 124, 2400-5.

Sun JY, Shi L, Gao XD, Hu SF (2012). Physical activity and risk of lung cancer: a meta-analysis of prospective cohort studies. Asian Pac J Cancer Prev, 13, 3143-7.

Tayyem RF, Shehadeh IN, Abumweis SM, et al (2013). Physical inactivity, water intake and constipation as risk factors for colorectal cancer among adults in Jordan. Asian Pac J Cancer Prev, 14, 5207-12.

Tremblay MS, Colley RC, Saunders TJ, Healy GN, Owen N (2010). Physiological and health implication of a sedentary lifestyle. Appl Physiol Nutr Metab, 35, 725-40.

Warburton DER, Charlesworth S, Ivey A, et al (2010). A systematic review of the evidence for Canada's physical activity guidelines. Int J Behav Nutr Phys Activity, 7, 39.

Warburton DER, Katzmarzyk PT, Rhodes RE, Shepard RJ (2007). Evidence-informed physical guidelines for Canadian adults. Can J Public Health, 98, 516-68.

Warburton DER, Nicol C, Bredin SS (2006). Health benefits of physical activity: the evidence. Can Med Assoc J, 174, 801-9.

Wellington Regional Strategy (WRS). The costs of physical inactivity. Toward a regional full-cost accounting perspective. Retrieved in June 2013 from http://www.gw.govt.nz.

Winzer BM, Whiteman DC, Reeves MM, Paratz JD (2011). Physical activity and cancer prevention: a systematic review of clinical trials. Cancer Causes Control, 22, 811-26.

World Cancer Research Fund/American Institute for Cancer Research, Food, Nutrition, Physical Activity, and the Prevention of Cancer: a Global Perspective, the Panel's Judgements Washington, DC: AICR 2007.

World Health Organization (2002). The World Health Report 2002, Reducing Risks, Promoting Healthy Life, WHO, Geneva 2002.

World Health Organization (2005). Preventing chronic diseases: a vital investment, WHO, Geneva 2005.

World Health Organization (2010). Global recommendation on physical activity for health. Geneva, Switzerland WHO press.

World Health Organization Global Status Report NCDs 2010. Retrieved in june 2010 from http://www.wcrf.org/cancer_ statistics/cancer_facts/physical_activity_recommendation. php.

World Health Organization. Retrieved in November 2008 from http://whqlibdoc.who.int/hq2003/WHO_NMH_NPH_ PAH_03.2.pdf.

Zhang J, Chaaban J (2013). The economic cost of physical inactivity in China. Prev Med, 56, 75-8. 